\title{
Performance Analysis of an Indirect Matrix Converter with a Reactor Free Boost Converter for Japanese 10-15 Mode Vehicle Driving Pattern
}

\author{
Goh Teck Chiang* Student Member, Jun-ichi Itoh ${ }^{*}$ Member
}

(Manuscript received Nov. 28, 2011, revised Jan. 20, 2012)

\begin{abstract}
This paper describes the performance and loss analysis of a three-port AC/DC/AC three-phase power converter based on the Japanese 10-15 mode vehicle driving pattern. The structure of the proposed circuit consists primarily of an indirect matrix converter (IMC) and a boost converter connected to the neutral point of the induction motor. The first part of this paper discusses a method for the optimization of the boost converter during single pulse modulation. The authors propose the implementation of feedforward compensation in the boost converter to suppress the battery ripple. Results show that the battery ripple is reduced by approximately $72 \%$ during single pulse modulation. The second part of this paper illustrates the behavior of the proposed converter when simulated under the Japanese 10-15 mode driving pattern. Converter losses under different conditions and circumstances are studied, and on the basis of the results, the optimal point of the power control for the converter is discussed.
\end{abstract}

Keywords: AC/AC conversion, DC/AC conversion, induction motor, modulation techniques

\section{Introduction}

Studies have proven that hybrid electric vehicles (HEVs) are able to reduce the $\mathrm{CO}_{2}$ emissions released in gasoline vehicles by $48 \%$. The reduction of $\mathrm{CO}_{2}$ emissions in automobiles is important for the effort to decrease global warming. In recent years, HEV research on power converters, electric motors, and batteries has been actively conducted.

The conventional converter, known as the back-to-back converter, is composed of a pulse width modulation (PWM) rectifier, a DC boost converter, and a PWM inverter and is commonly used in HEV systems ${ }^{(1)(2)}$. The structure of this converter is simple but requires a short maintenance interval, and its size is relatively large. Many studies have shown that a matrix converter (MC) is an alternative converter that is also applicable to $\mathrm{HEVS}^{(3)(4)}$. MCs can reduce the size of the converter and can achieve high efficiency and high reliability.

However, in HEV applications, the lack of DC bus voltage in the MCs requires additional switching devices to form an inverter and connect with the batteries, which is also known as a hybrid matrix converter ${ }^{(5)-(7)}$. In general, the use of additional devices results in higher losses and larger sizes.

On the other hand, two-stage MCs that have DC bus voltage have also been investigated for HEV applications ${ }^{\left({ }^{(9)}\right.}$. Their circuit topology has features similar to MCs but with high efficiencies and longer lifetimes due to the lack of electrolytic capacitors. Furthermore, they are smaller in size compared to the hybrid matrix converter because this circuit topology can easily connect with a DC voltage source and a boost converter ${ }^{(10)}$.

The authors previously proposed an AC/DC/AC circuit for HEV systems ${ }^{(11)}$. The proposed circuit has an advantage in

\footnotetext{
* Nagaoka University of Technology

1603-1, Kamitomioka-machi, Nagaoka 940-2188, Japan
}

terms of size by removing two passive components (the electrolytic capacitors and the boost reactor) from the converter. The boost converter utilizes the leakage inductance of the motor by connecting the batteries to the neutral point of the motor. In addition, the authors also demonstrated that the proposed converter is able to operate under PWM or single pulse modulation, which is suitable for HEV applications ${ }^{(12)}$.

However, since the proposed circuit is implemented with single pulse modulation, the neutral point voltage becomes a square-wave voltage with a frequency of three times the output frequency and an amplitude of 1/6 the DC link voltage. The voltage fluctuation affects the battery current due to the direct connection.

In the present paper, the authors propose to implement feedforward compensation into the controller of the boost converter. The compensation can balance the battery current and suppress the ripple during single pulse modulation that is caused by the neutral point voltage. Simulation and experimental results are provided to validate the proposed method.

Additionally, the authors discuss the performance of the proposed circuit under the Japan vehicle driving pattern (Japan 10-15 mode), which is recognized by the Japanese government ${ }^{(13)}$. The power converter in a hybrid system needs to run under different operations depending on the driving condition. In this analysis, the proposed circuit is tested under the Japanese 10-15 mode driving pattern for several different operations. The performance of the proposed circuit is analyzed and evaluated based on the Japanese 10-15 mode driving pattern.

\section{Circuit Topology}

Fig. 1 illustrates the energy flow of the hybrid system in an HEV. In a hybrid system that has two power sources (a gasoline generator and batteries), the converter can be controlled in various ways to deliver energy to the output source 


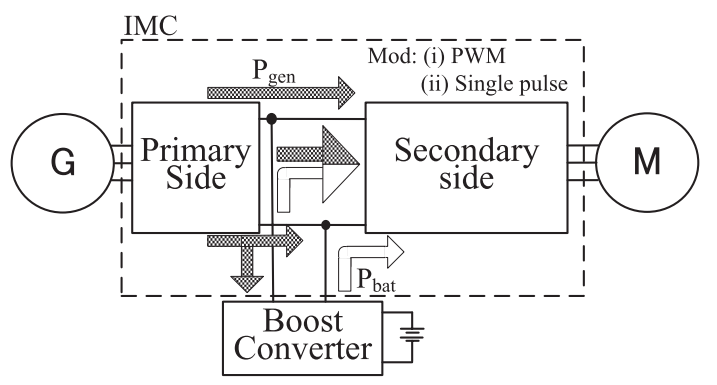

Fig. 1. Proposed circuit energy flow diagram

Table 1. Motoring operation modes

\begin{tabular}{|l|l|l|l|}
\hline Mode & $\begin{array}{l}\text { Primary side } \\
\text { (Pgen) }\end{array}$ & $\begin{array}{l}\text { Boost converter } \\
\text { (Pbat) }\end{array}$ & $\begin{array}{l}\text { Inverter } \\
\text { (Modulation) }\end{array}$ \\
\hline I & Full supply & Not applicable & PWM \\
\hline & Full supply & Not applicable & Single Pulse \\
\hline II & Variation & Max at $\mathrm{x} \%$ & PWM \\
\hline & Variation & Max at $\mathrm{x} \%$ & Single Pulse \\
\hline III & Max at $\mathrm{x} \%$ & Variation & PWM \\
\hline & Max at $\mathrm{x} \%$ & Variation & Single pulse \\
\hline
\end{tabular}

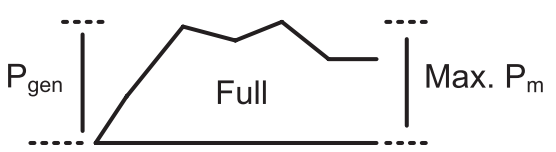

(a) Mode I

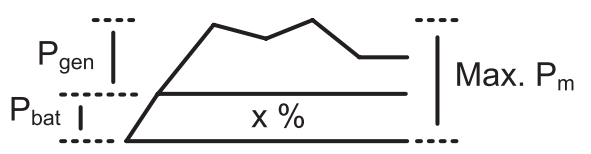

(b) Mode II

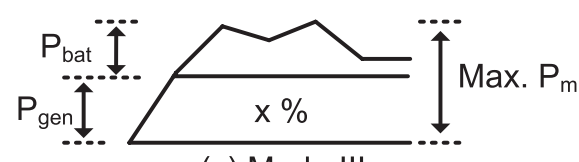

(c) Mode III

Fig. 2. Energy management in a HEV

(electric motor). As shown in Fig. 1, the generator power can be controlled in four ways and the battery power can be controlled in two ways for the motoring operation, where $P_{\text {gen }}=$ generator power, $P_{b a t}=$ battery power, and $P_{m}=$ required motor power. Based on the control of the input power, the power converter in a hybrid system is able to operate in six modes for the motoring condition. Table 1 illustrates the six operation modes of energy control for the motoring operation. Basically, the six operation modes can be classified into three modes, known as Mode I, Mode II, and Mode III, where the inverter modulation differs between PWM and single pulse modulation for these three modes.

Fig. 2 demonstrates the differences between the three operation modes. In Mode I, the battery power is zero, and the generator power provides the full power to drive the electric motor. In Mode II, the maximum battery power is set to a certain limit at $\mathrm{x} \%$, and the additional power required for the output source will be supplied from the generator power. On the other hand, in Mode III, the maximum generator power is set to a certain limit at $\mathrm{x} \%$, and the battery power is used to supply the variation power required for the output source. In

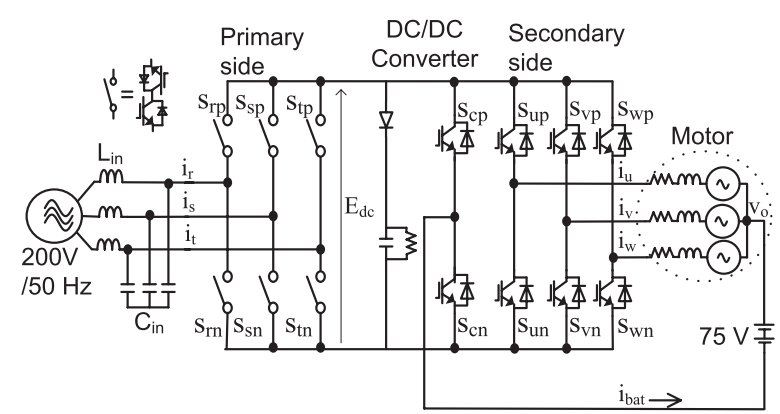

Fig. 3. Proposed circuit diagram

Mode III, the portion of the battery power is generally smaller than that of the battery power in Mode II.

The inverter that converts the input power to drive the electric motor is able to operate in two modes and is controlled by modulation (PWM and single pulse modulation). Due to the complexity in the control structure, the performance of the converter needs to be investigated, analyzed, and optimized in order to achieve high efficiency and energy savings for HEV applications.

Fig. 3 shows a circuit structure previously proposed by the authors ${ }^{(11)}$. The main circuit is an indirect matrix converter (IMC), and the DC link part of the IMC is connected with a DC boost converter and batteries. Moreover, the battery terminal connects to the neutral point of the motor and utilizes the leakage inductance of the motor as a boost reactor; this converter is also known as a reactor free boost converter. The implementation of the reactor free boost converter in the circuit further reduces the size, weight, and volume of the converter.

In the circuit structure of the IMC, the secondary side of the IMC is similar to the conventional voltage source inverter, and therefore, the inverter can function in PWM and single pulse operation. The fundamental operation and validity data have been discussed by the authors in Refs. (11) (12)(14). The reason to implement single pulse modulation into the proposed circuit is to (i) improve the voltage transfer ratio (VTR), which is the ratio defined as $\mathrm{v}_{\text {out }} / \mathrm{v}_{\text {in }}$, (ii) improve the efficiency by reducing the switching loss in the inverter at high speeds, and (iii) reduce the motor loss by reducing the inverter output current. References 12 and 14 show that single pulse modulation can improve the VTR of the IMC from 0.866 (PWM) to 0.97 (single pulse modulation).

However, under single pulse modulation, the reactor free boost converter faces a voltage fluctuation problem due to the neutral point connection. Since the boost converter is connected with the neutral point voltage, the fluctuation directly affects the battery current (neutral line).

\section{Single Pulse Operation}

3.1 Control Block Diagram Fig. 4 shows a control block diagram of the proposed circuit, which is based on the carrier comparison PWM. The primary side uses single phase modulation (Single leg mod. in Fig. 4) and includes a pulse pattern conversion to convert the voltage source switching patterns into the current source, where $i_{r}^{*}, i_{s}^{*}$, and $i_{t}^{*}$ represent the input current commands. The principle is to control the absolute value of the three-phase input voltage so that the 


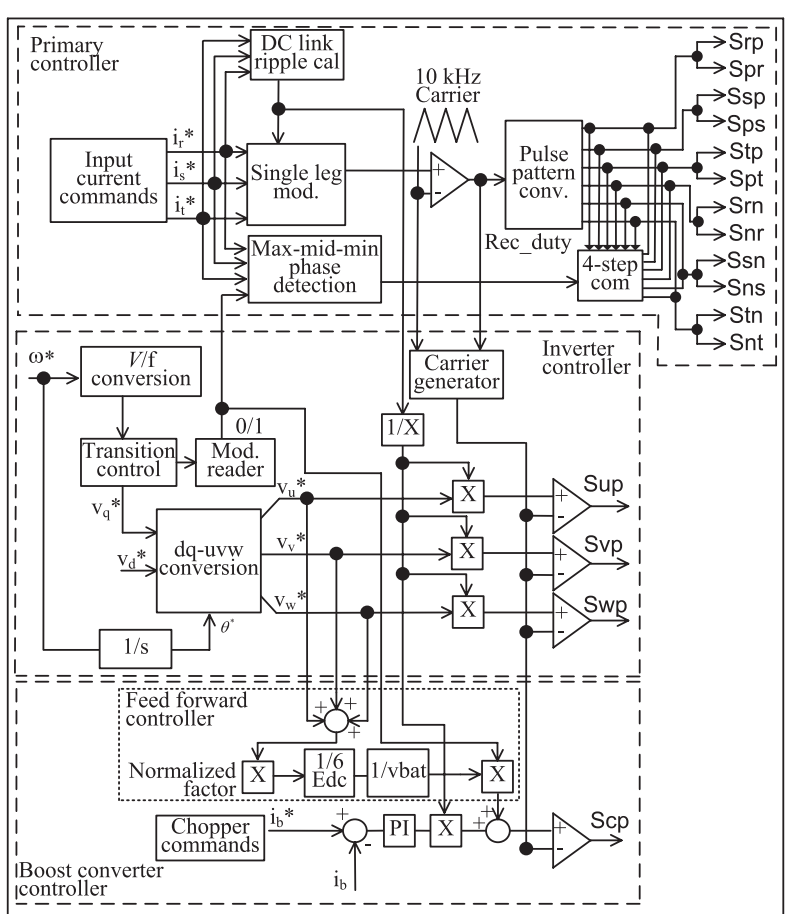

Fig. 4. Control block diagram

input voltage carrying the maximum phase absolute voltage is always selected; this selection corresponds to a switch that is always turned on. Then, the other two legs (consisting of the medium-phase absolute voltage and the minimum-phase absolute voltage) are in the switching state. The pulse pattern conversion is a simple logic selector that converts the voltage source PWM pulse pattern into the current source PWM pulse pattern. This technique enables the DC link voltage to be formed with a frequency six times higher than the input frequency.

In addition, the primary side includes a four-step commutation in the switching pattern to optimize the circuit performance $^{(15)}$. The implementation of regular dead time in the switching pattern of the primary side will cause the switches to open. The short period of dead time will cause the DC link to drop to zero, and therefore, the amplitude of the output voltage is decreased. In order to ensure the output voltage is not degraded by the DC link voltage, the four-step commutation is applied to avoid an open circuit. As a result, the VTR of the proposed circuit can reach 0.97 during single pulse modulation. For implementing dead time, the highest VTR is 0.92 , as shown in Ref. (12).

A carrier generator that can produce a variable carrier based on the primary side command $\left(\operatorname{Rec}^{*}\right)$ is used in the secondary side and the boost converter side. The secondary side includes a $V / f$ conversion to control the motor frequency and output voltage as constant values. The motor speed is adjusted proportionally to the output frequency. The transition control is based on the nonlinear control of the fundamental frequency amplitude of the output voltage, which proportionally compensates the amplitude of the output voltage command. The dqo-uvw transformation is applied to the secondary side with transition control, as shown in Fig. 4, where $v_{q}$ is the q-axis voltage control command, and $v_{d}$ is the d-axis voltage control command. The amplitude of $v_{q}$

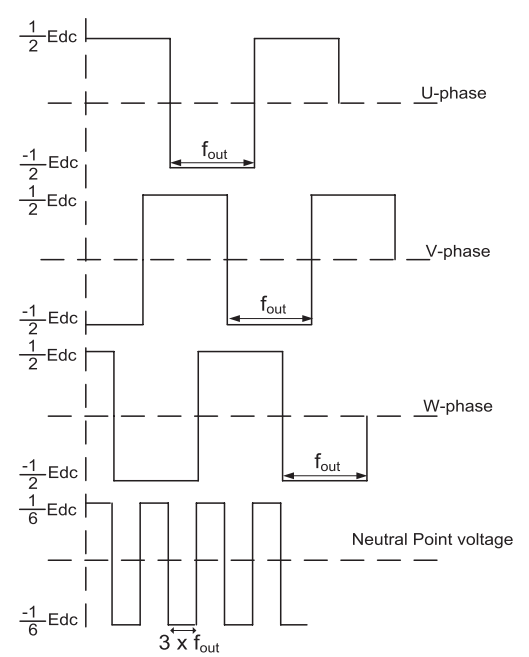

Fig. 5. Voltage fluactuation at netural point

will be extended in the overmodulation range according to the frequency. Then, the three-phase output voltage commands are calculated based on the dq conversion from the following equations:

$$
\begin{aligned}
& v_{u}=v_{d} \cos \omega t+v_{q} \sin \omega t \\
& v_{v}=v_{d} \cos \left(\omega t-\frac{2 \pi}{3}\right)+v_{q} \sin \left(\omega t-\frac{2 \pi}{3}\right) \\
& v_{w}=v_{d} \cos \left(\omega t+\frac{2 \pi}{3}\right)+v_{q} \sin \left(\omega t+\frac{2 \pi}{3}\right)
\end{aligned}
$$$$
\text { .................. }
$$

where $v_{u}, v_{v}$, and $v_{w}$ are the output voltage commands, and $\omega$ is the frequency.

The boost converter controller uses an automatic current regulator (ACR) to control the battery current. The PI gain of the ACR is multiplied by the DC link frequency compensator and is then compared with the carrier comparison PWM to obtain the switching pattern.

However, during single pulse modulation, the neutral point voltage produces a high-frequency square waveform. The square wave fluctuation affects the battery current and results in the boost converter malfunctioning.

3.2 Feedforward Compensation As previously discussed, the neutral point connection consists of a high fluctuation that affects the boost converter operation. Fig. 5 shows that the frequency of the fluctuation is three times the output frequency, and the amplitude of the fluctuation is $1 / 6$ of $E_{d c}$.

The fundamental square wave output voltage for the inverter is given by

$$
V_{u v}=\frac{\sqrt{6}}{\pi} E_{d c}
$$

where $V_{u v}$ is the output line voltage, and $E_{d c}$ is the DC link voltage. Each of the output phase voltages based on the neutral point of the DC link voltage are switched at 0 or 180 degrees, and the neutral point voltage will be the sum of the three output phase voltages, which is $\pm 1 / 6 E_{d c}$. Furthermore, the voltage of the boost converter must be smaller than the DC link voltage, which can be expressed as the following condition: 


$$
\begin{aligned}
\frac{E_{d c}}{2} & >\frac{1}{6} E_{d c}+V_{b a t} \\
E_{d c} & \geq 3 V_{b a t} \ldots \ldots
\end{aligned}
$$

where $V_{b a t}$ is the battery voltage, and $E_{d c}$ is the DC link voltage.

In order to balance the fluctuation, feedforward control is proposed to be applied to the boost converter. The block diagram in Fig. 4 shows that the switching signals from the inverter stage are first obtained and then normalized with the DC link voltage and the battery voltage. The "mod reader" is used to distinguish between PWM and single pulse modulation. Once single pulse modulation is activated $(0=$ off, $1=$ on), the feedforward signal will be sent to the ACR controller. The output waveform of the feedforward control has the same frequency and amplitude as the neutral point voltage but in a reversed form. This signal is then cancelled with the actual fluctuation waveform in the PI controller to suppress battery ripple.

\section{Simulation Results}

Table 2 shows the simulation parameters. Fig. 6 shows the operation waveform of the proposed circuit transforming from PWM into single pulse modulation. The output voltage is controlled by $V / f$ conversion, where the output frequency

Table 2. Simulation parameters

\begin{tabular}{|l|l|}
\hline Input voltage & $200 \mathrm{~V}$ \\
\hline Input frequency & $50 \mathrm{~Hz}$ \\
\hline Carrier frequency & $10 \mathrm{KHz}$ \\
\hline Output frequency & $0-50 \mathrm{~Hz}$ \\
\hline DC source voltage & $75 \mathrm{~V}$ \\
\hline Leakage inductance & $5 \mathrm{mH}$ \\
\hline Low pass filter (cut-off) & $2 \mathrm{kHz}$ \\
\hline RL load (Resistance) & $25 \Omega$ \\
\hline Inductance & $5 \mathrm{mH}$ \\
\hline
\end{tabular}

is proportional to the output voltage. The transition period starts from $35 \mathrm{~Hz}$ and is completed at $50 \mathrm{~Hz}$. Starting from $50 \mathrm{~Hz}$, the inverter keeps the output voltage constant and operates at single pulse modulation. Feedforward compensation is applied to the boost converter while the transition starts.

In order to validate the performance of the boost converter, the battery current is controlled at three different points. At point $\mathrm{A}$, the battery current is increased to $5 \mathrm{~A}(375 \mathrm{~W})$; consequently, the input current notices a reduction in power because the battery power is used to drive the motor. At point $\mathrm{B}$, the battery current is reduced to $1 \mathrm{~A}(75 \mathrm{~W})$, and this can confirm that the boost converter is operating well even though the output frequency is changing. Once single pulse modulation starts, the battery current is increased to $5 \mathrm{~A}(375 \mathrm{~W})$ again at point $\mathrm{C}$. From the input current waveform, a reduction in the amplitude of the current can be noticed, and this phenomenon can confirm the functionality of the boost converter.

Notice the DC component of the output current waveform changes according to the battery current. Therefore, onethird of the battery current is imposed into the inverter current, and the DC polarity of the inverter current will be affected.

\section{Experimental Results}

Table 3 shows the experimental parameters. Fig. 7 demonstrates the single pulse modulation experimental results (a)

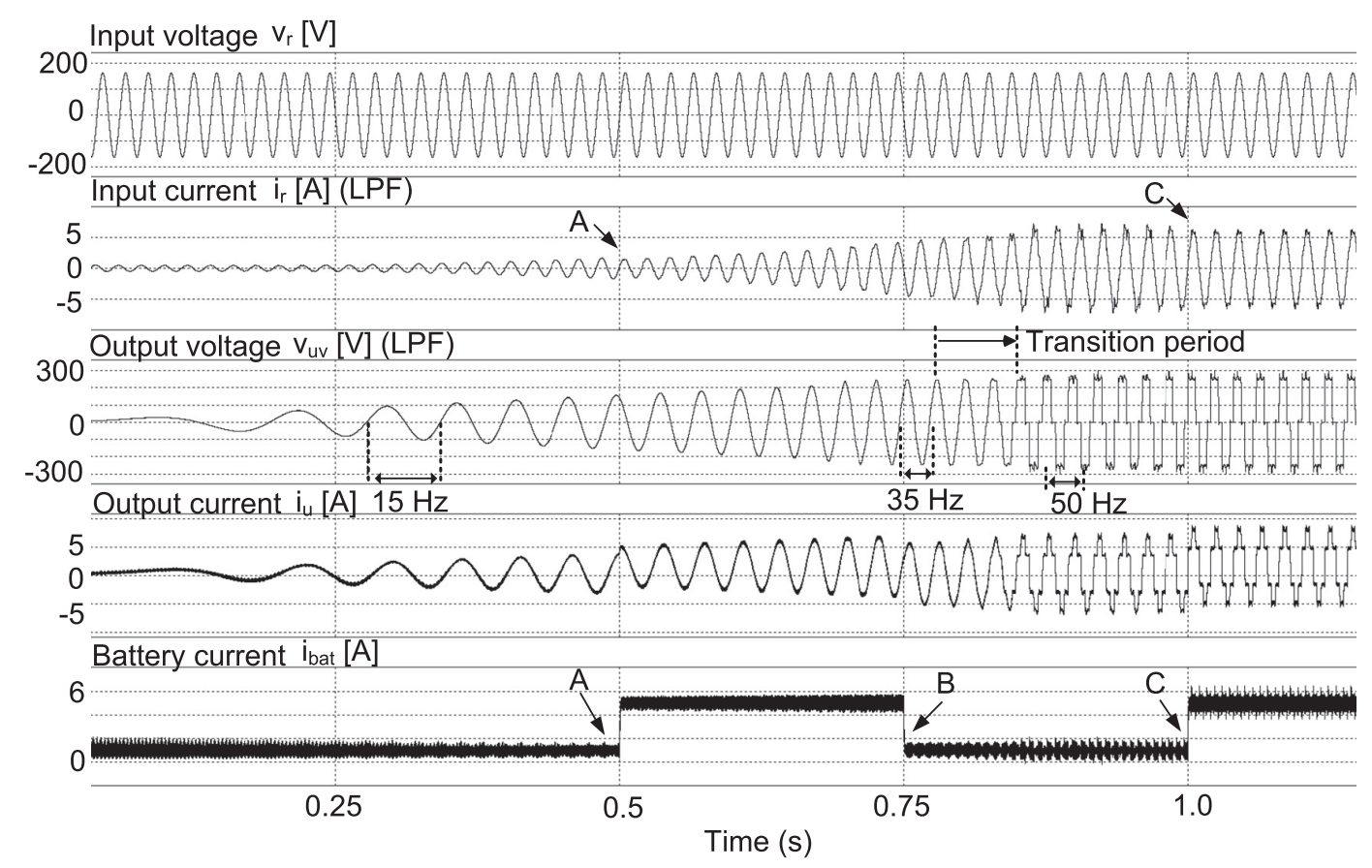

Fig. 6. Simulation result 


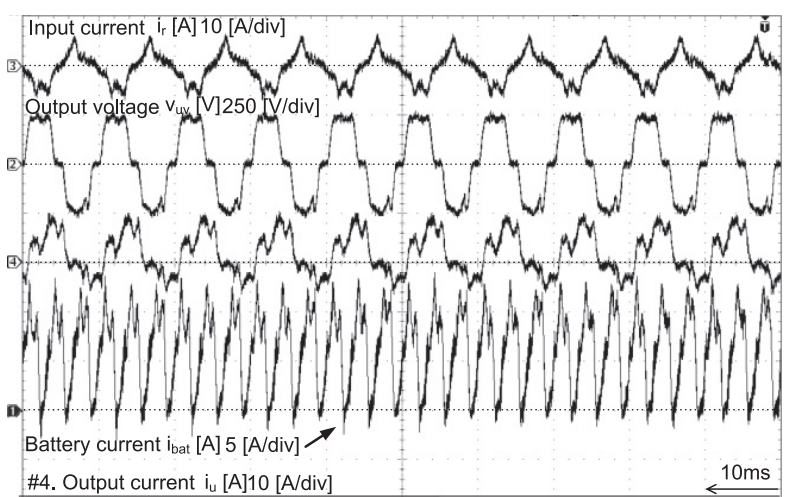

(a) Without feedforward compensation

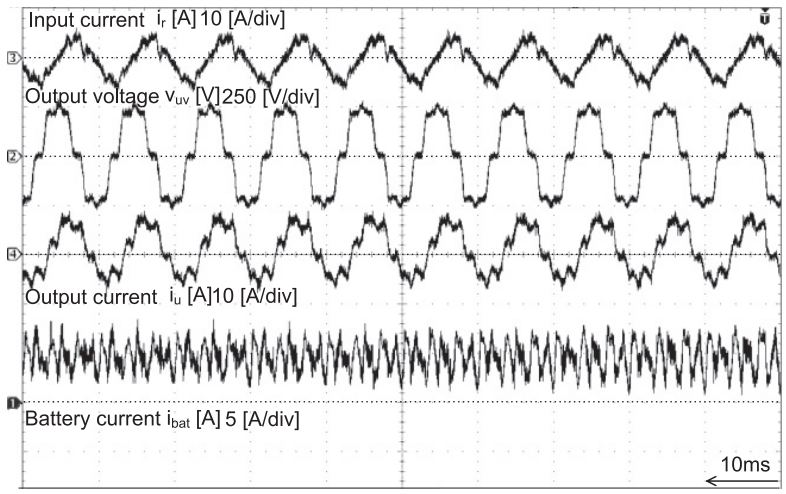

(b) With feedforward compensation

Fig. 7. Experiment results

without feedforward compensation and (b) with feedforward compensation. The battery current fluctuates at a very high amplitude (peak to peak $=15 \mathrm{~A}$ ), and this results in the harmonic components of the output current changing. On the other hand, Fig. 7(b) demonstrates a better result than Fig. 7(a). The feedforward compensation suppressed ripple in the battery current by approximately $72 \%$ (peak to peak = 4 A). Furthermore, the output current improved significantly. Since the IMC is a direct-type AC converter, the impact on the output current directly affects the input current. As a result, the input current in Fig. 7(b) shows better harmonic components than the input current in Fig. 7(a).

Fig. 8 shows the total harmonic distortion (THD) characteristics of the input current and output current, which are represented by the black line and the dotted line, respectively. From the comparison, the THD of the input current significantly improved by approximately $22 \%$ after implementing feedforward compensation. Likewise, the THD of the output current improved by $38 \%$.

\section{Loss Analysis}

\subsection{Loss Comparison between PWM and Single Pulse} Modulation Fig. 9 shows the loss comparison between PWM and single pulse modulation under ideal conditions. Table 4 shows the simulation parameters. Notice that although the output power is equivalent, the voltage and current for both results are different. The tested condition is ideal, and dead time and the low-pass filter are not applied in the simulation. Also, the motor loss is not included in the result.

In single pulse modulation, the switching loss of the inverter is greatly reduced due to the implementation of a

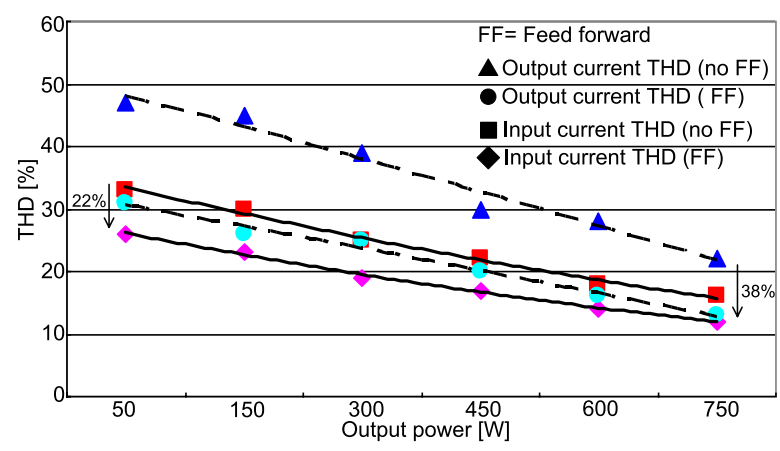

Fig. 8. Current THD comparison

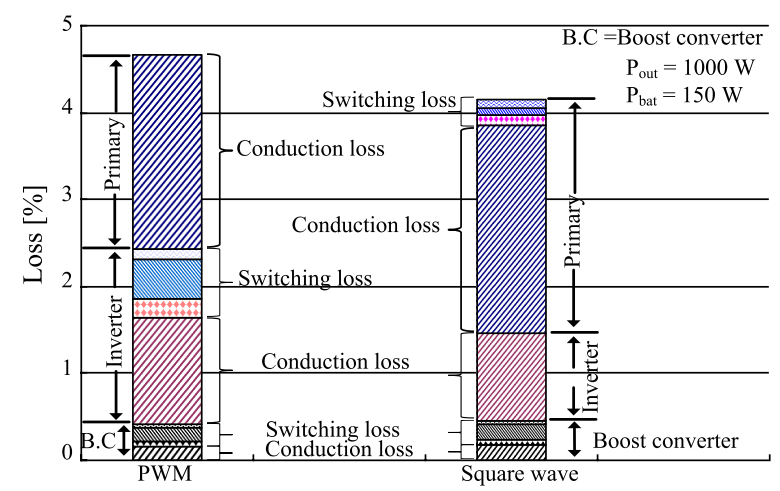

Fig. 9. Loss comparison

Table 4. Simulation parameters

\begin{tabular}{|l|l|l|l|}
\hline \multicolumn{2}{|l|}{ PWM } & \multicolumn{2}{|l|}{ Single Pulse Modulation } \\
\hline Input frequency & $50 \mathrm{~Hz}$ & Input frequency & $50 \mathrm{~Hz}$ \\
\hline Input phase voltage & $144 \mathrm{~V}$ & Input phase voltage & $144 \mathrm{~V}$ \\
\hline Output frequency & $50 \mathrm{~Hz}$ & Output frequency & $50 \mathrm{~Hz}$ \\
\hline Carrier frequency & $10 \mathrm{kHz}$ & Carrier frequency & $10 \mathrm{kHz}$ \\
\hline $\begin{array}{l}\text { Output phase } \\
\text { voltage }\end{array}$ & $105 \mathrm{~V}$ & $\begin{array}{l}\text { Output phase } \\
\text { voltage }\end{array}$ & $140 \mathrm{~V}$ \\
\hline DC source & $75 \mathrm{~V}$ & DC source & $75 \mathrm{~V}$ \\
\hline
\end{tabular}

square wave switching pattern in the inverter. This modulation benefits the proposed circuit because in PWM, the switching freque ncy for the inverter side is nearly two times the switching frequency for the primary side (approximately $20 \mathrm{kHz}$ per switching cycle). In single pulse modulation, the switching loss occurs in the primary side, but the losses only applied to those active switching devices with a $10 \mathrm{kHz}$ switching frequency. As a result, the switching loss in the primary side is lower than that in the inverter side.

On the other hand, the total loss of the boost converter in single pulse modulation is slightly higher than that in PWM. This is because the effect of the neutral point voltage fluctuation results in battery ripple higher than that of PWM. The battery ripples resulting from the switching loss in single pulse modulation increased compared to those in PWM. In a comparison with an identical output frequency, single pulse modulation provides $0.35 \%$ better efficiency than PWM.

6.2 HEV Driving Cycle \& PLECS Loss Analysis Method As discussed in the introduction, the power converter in a hybrid system is required to work in a variety of operations. In order to optimize the converter performance, the proposed converter is simulated under a Japanese 10-15 mode driving pattern using simulator PLECS ${ }^{(16)}$. Under the 


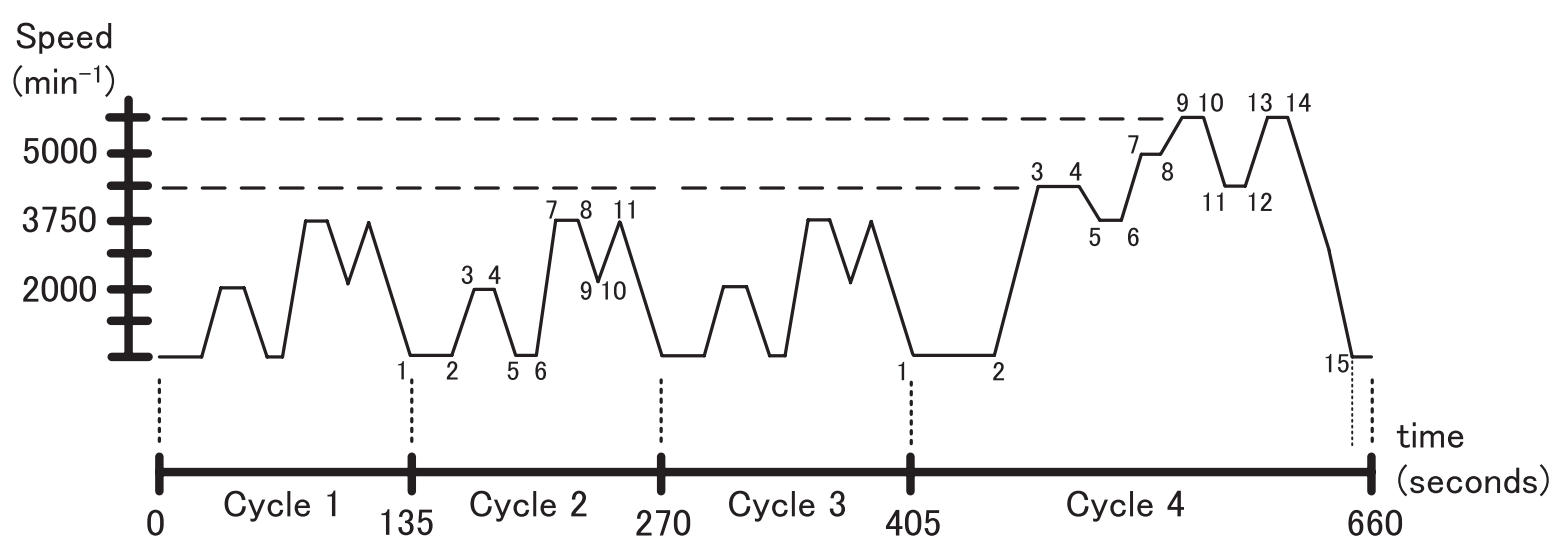

Fig. 10. Japanese 10-15 mode vehicle driving pattern

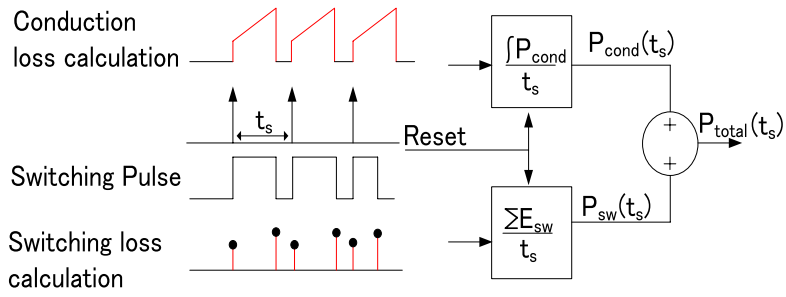

Fig. 11. PLECS loss calculation module

driving cycle, the proposed converter is controlled to work in different operation modes (as indicated in Table 1). The results from these different operations are then analyzed and used to study the performance behavior of the proposed converter. Note that this analysis monitors the converter behavior without including real-time factors such as contact forces (applied force, friction) or field forces (gravity, vehicle weight).

Fig. 10 shows the Japanese 10-15 mode driving pattern. The driving cycle is composed of a total of four cycles and is completed in 660 seconds. Cycles 1, 2, and 3 are divided into eleven sections each, and Cycle 4 is divided into fifteen sections; the average power and efficiency of the converter are used to analyze the performance.

Fig. 11 shows the loss analysis module from the PLECS simulator. The module is connected to each of the individual IGBTs and diodes in the proposed circuit, which has a total of 40 modules. The module calculates the losses based on the switching pulse and switching period $(t s)$ of each individual device. The turn-on pulse triggers the start of the calculation for the conduction loss $\left(\mathrm{P}_{\mathrm{con}}\right)$ and then resets the calculation at the turn-off pulse. The switching loss $\left(\mathrm{P}_{\mathrm{sw}}\right)$ is calculated from the sum of the energy divided by the sample time. The losses are calculated by a C-script program based on the datasheets of each device. The specifications of the devices are listed in Table 5 and Ref. (17) (18).

Table 1 in Chapter 2 shows the six operation modes that are tested with the proposed circuit in this analysis. The input power is controlled based on the flowchart shown in Fig. 12 ${ }^{(19)}$. Fig. 12(a) shows the input power management for Mode II, and Fig. 12(b) shows the input power management for Mode III. $\mathrm{P}_{\mathrm{m}}$ is the motor power, $\mathrm{P}_{\mathrm{bat}}$ is the battery power, $\mathrm{P}_{\text {gen }}$ is the generator power, and SOC is the state of charge of the battery. On the other hand, the inverter is controlled with PWM or PWM combined with single pulse modulation for each mode. Note that in this analysis, the regenerative energy
Table 5. Simulation parameters

\begin{tabular}{|l|l|}
\hline Input voltage & $200 \mathrm{~V}$ \\
\hline Input frequency & $50 \mathrm{~Hz}$ \\
\hline Carrier frequency & $10 \mathrm{KHz}$ \\
\hline Output frequency & $\begin{array}{l}\text { Vary according to speed } \\
\text { command }\end{array}$ \\
\hline DC source & $\begin{array}{l}100 \mathrm{~V}(\mathrm{PWM}) / 75 \mathrm{~V} \text { (Single } \\
\text { pulse modulation) }\end{array}$ \\
\hline Leakage Inductance & $5 \mathrm{mH}$ \\
\hline Load: EMF voltage & $\mathrm{R}=2 \Omega, \mathrm{L}=5 \mathrm{mH}$ \\
\hline & $115 \mathrm{~V}(3-$ phase AC) \\
\hline IGBT (Primary side) & $1 \mathrm{MBH} 30 \mathrm{D}-060$ \\
\hline $\begin{array}{l}\text { IGBT (Inverter \& boost } \\
\text { converter) }\end{array}$ & $2 \mathrm{MBI} 50 \mathrm{~N}-060$ \\
\hline
\end{tabular}

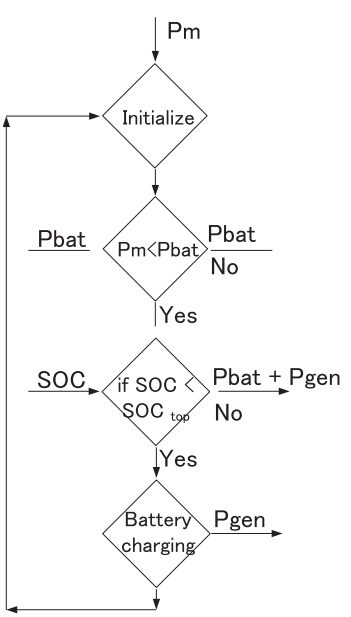

(a) Mode II

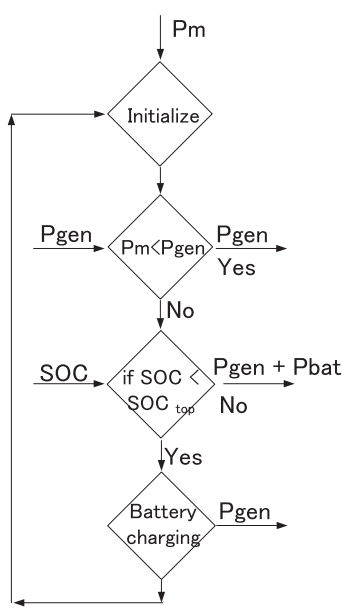

(b) Mode III
Fig. 12. Input power management flowchart

and state of charge are in ideal conditions.

6.2.1 Simulation Results Fig. 13 shows the simulation results for (a) Mode II and (b) Mode III. The simulation parameters are listed in Table 5. The load consists of a small resistance, inductance, and back-EMF voltage. The back-EMF voltage is sinusoidally controlled proportional to the speed command using dqo-abc transformation.

The output voltage is controlled by $V / f$ conversion, as illustrated in the block diagram in Fig. 4. From $0 \mathrm{~Hz}$ to $35 \mathrm{~Hz}$, the output voltage is proportional to the output frequency. Starting from $35 \mathrm{~Hz}$, the output voltage remains constant, and the 


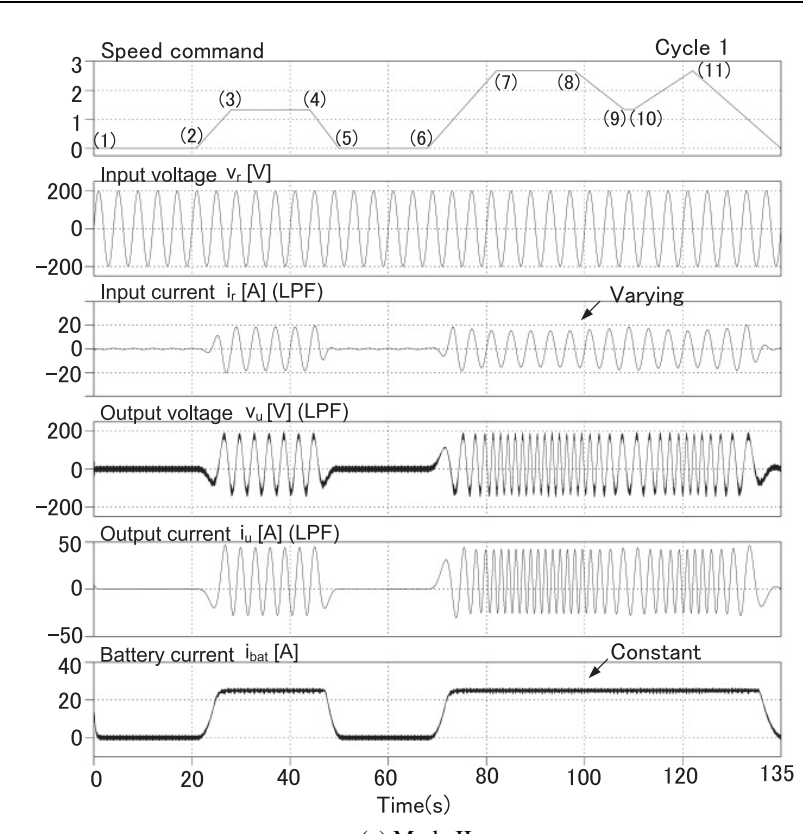

(a) Mode II

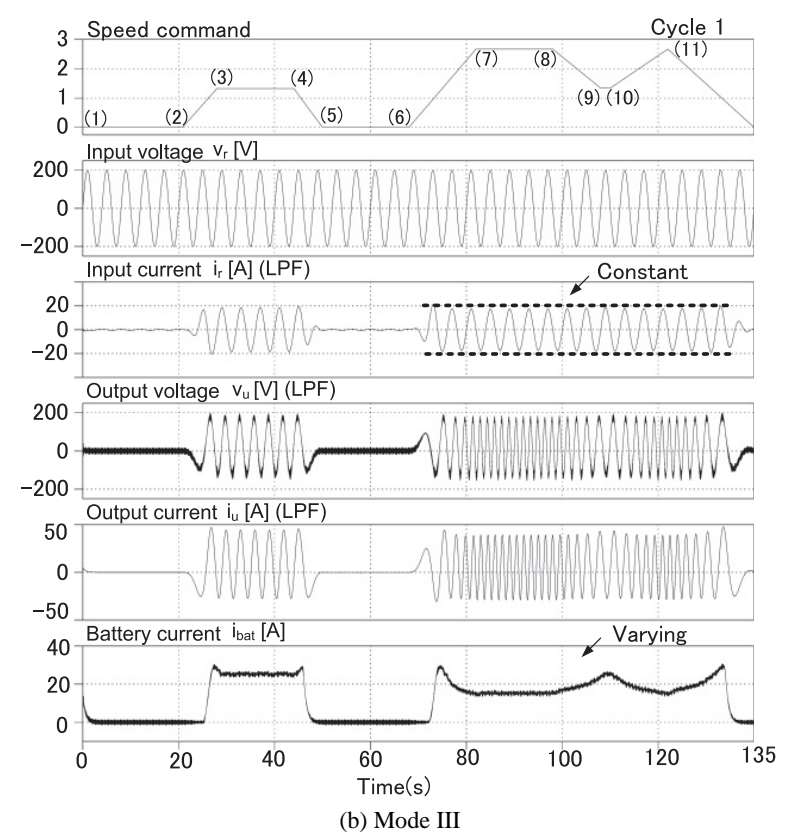

Fig. 13. PLECS simulation results (PWM only)

frequency changes according to the speed command. In the results, speed command $1=50 \mathrm{~Hz}$, and assuming an induction motor, it equals $120 \times \mathrm{f} / \mathrm{N}=1500 \mathrm{RPM}$, where $\mathrm{f}$ is the output frequency, and $\mathrm{N}=4$ poles. The speed command is controlled similarly to Cycle 1 of the Japanese 10-15 mode driving pattern.

In Fig. 13(a), the battery current starts immediately as the motor accelerates; then, once the battery power reaches its maximum, the input current immediately provides high power to the motor. The battery power is fixed at $30 \%$ of the motor power, and the input current waveform varies because the generator power supplies the additional power to the motor.

In Fig. 13(b), the generator power is fixed at $70 \%$ of the motor power. The battery power supplies more power when the motor power requires it. The battery current varies from

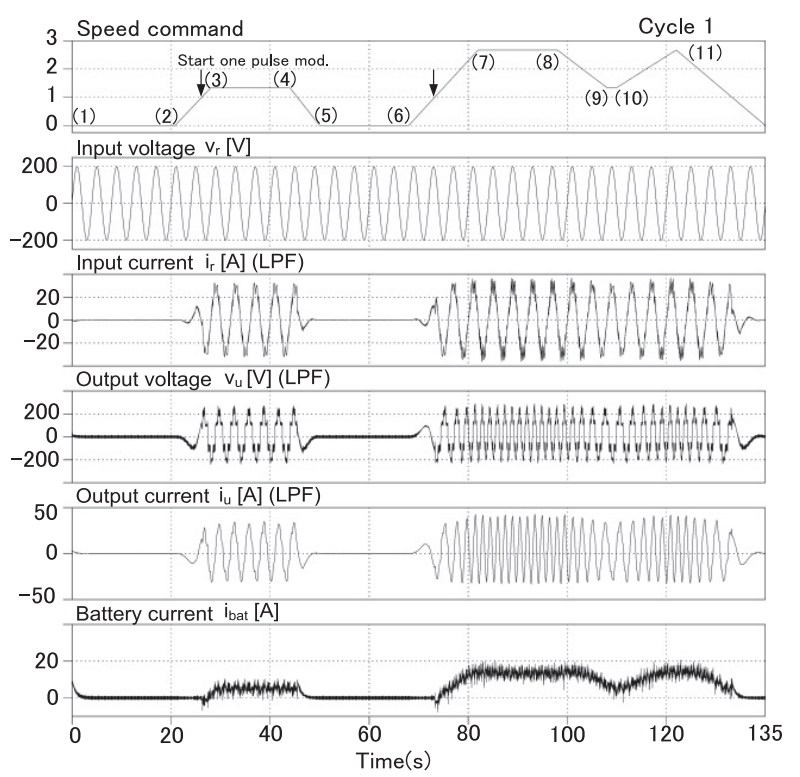

Fig. 14. Mode III simulation results (PWM \& single pulse)

70 to $130 \mathrm{~A}$ according to the change in output power; however, the input current remains constant.

On the other hand, Fig. 14 shows the Mode III operation waveform controlled by a combination of PWM and single pulse modulation. Note that due to the voltage limitation (refer to Eq. (3)), the battery voltage changes to $75 \mathrm{~V}$. In this result, the transition control from PWM to single pulse modulation is designed to start near 1500 RPM. The modulation changes from PWM to single pulse modulation if the speed command is larger than 1 ; the reverse occurs if the speed command is less than 1. The change in shape of the output voltage waveform represents single pulse modulation.

6.2.2 Analysis Results of Cycle 1 of Japanese 10-15 Mode This section discusses the efficiency that the proposed converter could achieve in Cycle 1 of the Japanese 1015 mode driving pattern. The analysis condition is ideal, and the dead-time effect, filter loss, and motor loss are not considered in the results. In this result, the battery power for Modes II and III is $30 \%$ of the motor power, and the generator power for both modes is $70 \%$ of the motor power.

The analysis result in Fig. 15 shows that Modes II and III can achieve higher efficiency than Mode I. The losses in the primary side of the IMC are able to be reduced by using the battery power from the boost converter to drive the electric motor. However, the efficiencies of all three modes decrease from $60 \mathrm{~s}$. The average efficiency is within the range of $93.5 \%$ to $94 \%$. This is because the output frequency increases, and the PWM pulse patterns cause high switching loss in the inverter. In order to reduce the switching loss, single pulse modulation is applied in the high output frequency area.

Fig. 16 shows the analysis results for the inverter with PWM combined with single pulse modulation. The battery power for Mode II is $15 \%$ of the output power, and that of Mode III is $10 \%$ of the output power. The modulation control is equivalent to that in Fig. 14, as discussed in the previous chapter. Mode I is able to achieve the highest efficiency among the three modes in the high-frequency area $(60 \mathrm{~s}$ to 


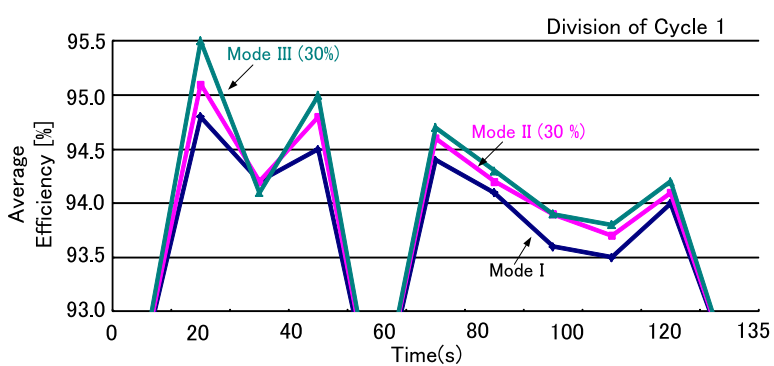

Fig. 15. Efficiency analysis in Cycle 1 of the Japanese 10-15 mode driving pattern (PWM, $\mathrm{P}_{\text {bat }}=30 \%$ of $\mathrm{P}_{\mathrm{m}}$ in Mode II, and $\mathrm{P}_{\mathrm{bat}}=30 \%$ of $\mathrm{P}_{\mathrm{m}}$ in Mode III)

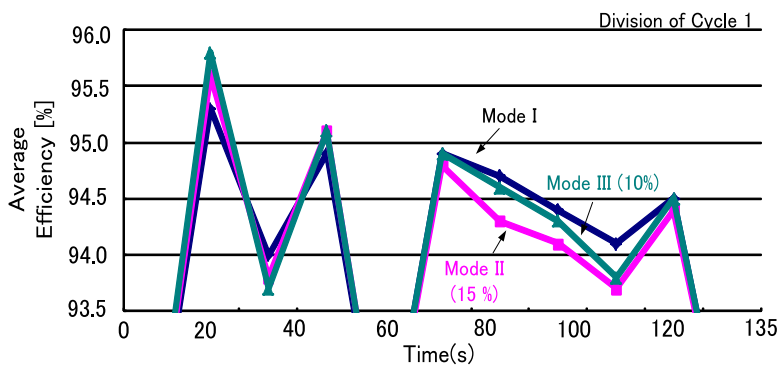

Fig. 16. Efficiency analysis in Cycle 1 of the Japanese 10-15 mode driving pattern (PWM + single pulse modulation, $\mathrm{P}_{\text {bat }}=15 \%$ of $\mathrm{P}_{\mathrm{m}}$ in Mode II, and $\mathrm{P}_{\text {bat }}=10 \%$ of $\mathrm{P}_{\mathrm{m}}$ in Mode III)

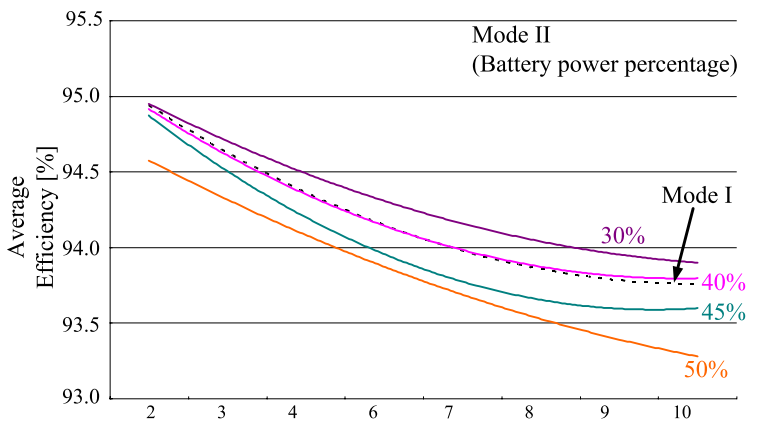

(a) Mode II and the battery power percentage (PWM)

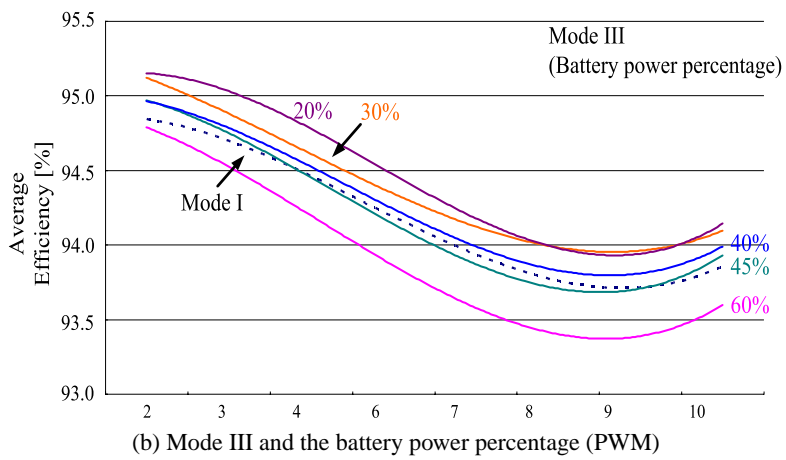

Fig. 17. Analysis of the battery power management

$125 \mathrm{~s})$. The efficiency range of the three modes is between $94 \%$ and $95 \%$. During single pulse modulation, the boost converter consists of a higher loss due to the occurrence of ripple in the battery current, which is affected by the neutral point connection. As shown in Fig. 14, the battery ripple becomes larger, which results in an increase in switching loss. As a result, the efficiencies of Mode II and Mode III are slightly lower than that of Mode I.

Fig. 17 shows the analysis studies on the battery ratio be-

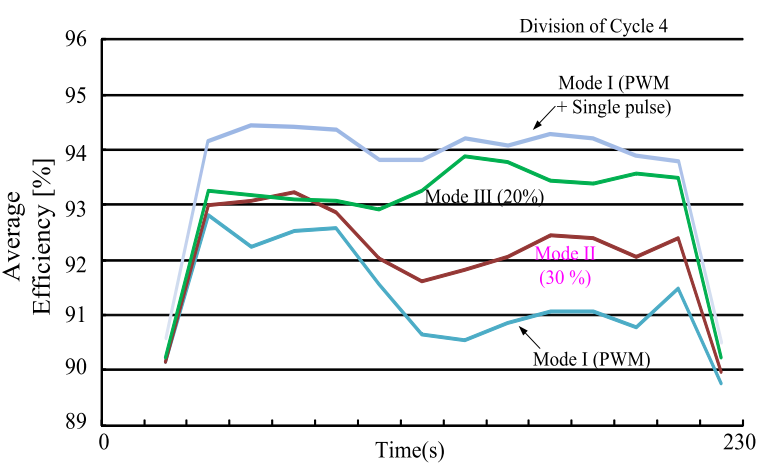

Fig. 18. Efficiency analysis in Cycle 4 of the Japanese 10-15 mode driving pattern (PWM + single pulse modulation)

tween (a) Mode II and (b) Mode III. In these analysis results, the ratio of the battery power changes from $20 \%$ to $50 \%$. That is, the generator power reduces from $80 \%$ to $50 \%$, and the proposed converter is controlled with PWM only under Cycle 1 . The battery voltage is equivalent in all conditions. Note that the results where the speed command equals to zero are not included in the graph.

For Mode II (Fig. 17(a)), it can be seen that when the battery power equals $40 \%$, the efficiency is almost equivalent to that of Mode I (dotted line). When the battery power is $30 \%$ of the output power, the proposed converter achieves a better efficiency than in Mode 1 . However, when the battery power is more than $45 \%$, the efficiency starts dropping due to the high conduction loss at the boost converter because of high battery current.

Note that in the proposed circuit, the output power for the inverter is expressed as

$$
P_{\text {out }}=v_{u} i_{u}^{*}+v_{v} i_{v}^{*}+v_{w} i_{w}^{*}+\frac{1}{3} i_{\text {bat }}\left(v_{u}+v_{v}+v_{w}\right) \cdots \cdots
$$

where $v_{u}, v_{v}$, and $v_{w}$ are the output phase voltages (RMS), $i_{u} *$, $i_{v} *$, and $i_{w^{*}}$ are the inverter currents (RMS), and $i_{b a t}$ is the battery current. Therefore, high battery current will result in an increase in output power; consequently, the input current will increase, and the resulting conduction loss in the primary side is increased.

For Mode III (Fig. 17(b)), the efficiency becomes equal to that of Mode I when the battery power is near $45 \%$ of the motor power. The efficiency is higher than in Mode I, provided the battery power is between $20 \%$ and $30 \%$ of the output power.

Based on these two results, the proposed circuit needs to be controlled under these conditions (PWM only) while operating in Mode II and Mode III, where the battery power of the proposed circuit should be designed at approximately $30 \%$ of the output power in order to maintain high-efficiency driving.

6.2.3 Analysis Results of Cycle 4 This section discusses the efficiency of the proposed converter while operating in Cycle 4 of the Japanese 10-15 mode driving pattern. Cycle 4 is also considered a high-speed driving region in the Japanese 10-15 mode driving pattern. The proposed circuit is controlled by combining PWM with single pulse modulation (similar to that shown in Fig. 14).

Fig. 18 shows the analysis results (similar to Fig. 16), and Mode I represents the highest efficiency among Mode II, 


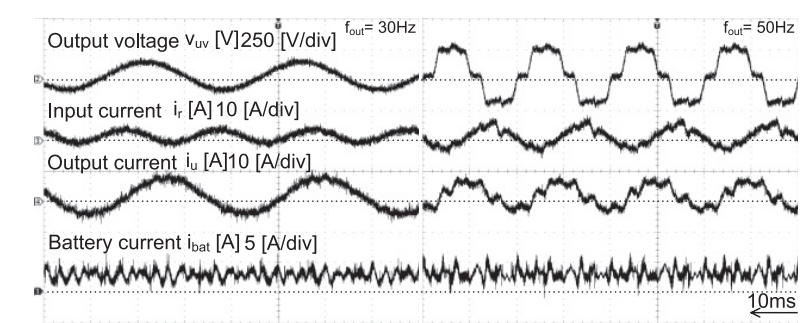

Fig. 19. Experimental results comparison between PWM and single pulse modulation

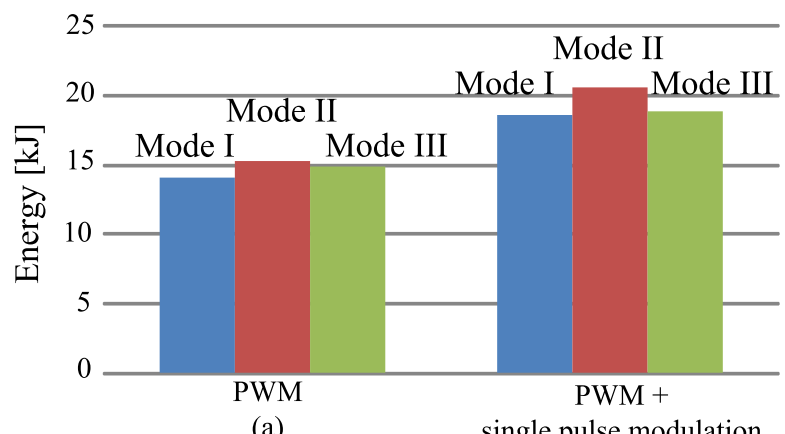

(b)

Fig. 20. Energy consumption chart for the proposed converter under different operation modes and modulations

Mode III, and PWM Mode I. In this result, the battery power is $30 \%$ for Mode II and 20\% for Mode III. Mode III presents the second highest efficiency because the battery current varies according to the required output power. As the battery power becomes low, the efficiency becomes closer to that of Mode I.

In Mode II, where the battery power is always constant at $30 \%$ of the output power, the efficiency is the third lowest for single pulse modulation. The losses are high because of the high conduction loss (high battery current) in the boost converter and the input current distortion in the primary side.

As shown in Fig. 14 from $60 \mathrm{~s}$ to $125 \mathrm{~s}$, the input current is distorted due to the high output frequency of the six-step output current waveform. The poor harmonic components in the input current result in higher losses in the primary side, especially once the input current becomes low. The input LC filter needs to be optimized in order to improve the input current during single pulse modulation. Overall, PWM Mode I shows the worst performance in high-speed driving. The efficiency can be improved by approximately $3 \%$ by implementing single pulse modulation into the PWM in the inverter.

Fig. 19 shows the experimental results between PWM and single pulse modulation. The experimental parameters are the same as in Table 2. The output frequency for PWM is $30 \mathrm{~Hz}$, and for single pulse modulation, it is $50 \mathrm{~Hz}$. The battery voltage is $75 \mathrm{~V}$ for both results, and the battery current is controlled at $2 \mathrm{~A}$. The results demonstrate that the battery current contains ripple slightly higher than the PWM. Furthermore, the input current distortion that is caused by the the six-step output waveform becomes significant.

\subsubsection{Energy Analysis for Japanese 10-15 Mode}

This section discusses the total energy consumption chart of the proposed circuit under the 10-15 mode cycle. Fig. 20
Table 6. Power management

\begin{tabular}{|c|c|c|}
\hline & PWM & PWM + 1 pulse mod. \\
\hline \multirow[t]{2}{*}{ Mode I } & $P_{\text {gen }}=P_{\text {out }}$ & $P_{\text {gen }}=P_{\text {out }}$ \\
\hline & $\mathrm{P}_{\text {bat }}=0 \mathrm{~W}$ & $P_{\text {bat }}=0 \mathrm{~W}$ \\
\hline \multirow[t]{2}{*}{ Mode II } & $P_{\text {gen }}=P_{\text {out }}-P_{\text {bat }}$ & $P_{\text {gen }}=P_{\text {out }}-P_{\text {bat }}$ \\
\hline & $\mathrm{P}_{\text {bat }}=30 \%$ of $\mathrm{P}_{\text {out }}$ & $P_{b a t}=15 \%$ of $P_{\text {out }}$ \\
\hline \multirow[t]{2}{*}{ Mode III } & $\mathrm{P}_{\text {gen }}=70 \%$ of $\mathrm{P}_{\text {out }}$ & $P_{\text {gen }}=90 \%$ of $P_{\text {out }}$ \\
\hline & $P_{\text {bat }}=P_{\text {out }}-P_{\text {gen }}$ & $P_{\text {bat }}=P_{\text {out }}-P_{\text {gen }}$ \\
\hline $\begin{array}{l}\text { Rated output } \\
\text { power }\end{array}$ & $6000 \mathrm{~W}$ & $8000 \mathrm{~W}$ \\
\hline $\begin{array}{l}\text { Time for cycle } 1 \\
\sim \text { cycle } 3\end{array}$ & \multicolumn{2}{|c|}{$\begin{array}{l}20 s-7 s-15 s-7 s-16 s-14 s-15 s-10 s-2 s- \\
12 s-17 s \text { (one complete cycle) }\end{array}$} \\
\hline Time for cycle 4 & \multicolumn{2}{|c|}{$\begin{array}{l}65 s-18 s-12 s-4 s-4 s-16 s-10 s-11 s-10 s \\
-10 s-4 s-22 s-5 s-30 s\end{array}$} \\
\hline
\end{tabular}

shows the circuit operated by (a) PWM and (b) PWM with single pulse modulation transformation. In each result, the consumed energies are compared among the three modes. The simulation parameters are consistent with those in Section 6.2. The power management is shown in Table 6 .

The average consumed energies for (a) under each mode are $300 \mathrm{~J} / \mathrm{sec}, 326 \mathrm{~J} / \mathrm{sec}$, and $316 \mathrm{~J} / \mathrm{sec}$, respectively. As for (b), the average consumed energies are $395 \mathrm{~J} / \mathrm{sec}, 437 \mathrm{~J} / \mathrm{sec}$, and $402 \mathrm{~J} / \mathrm{sec}$. Mode II represents the largest amount in (a) and (b) at approximately $15 \mathrm{~kJ}$ and $21 \mathrm{~kJ}$, respectively.

\section{Conclusion}

The authors discussed the performance of the proposed circuit by demonstrating two different sections. The first section showed the proposed circuit operated by single pulse modulation. Feedforward compensation was proposed to be applied in the boost converter during single pulse modulation to suppress battery ripple, and approximately $72 \%$ has been suppressed. The analysis data also showed that the proposed converter is able to achieve a high efficiency that is approximately equivalent to that of the PWM drive.

The second section considered the overall performance of the proposed circuit runs on the Japanese 10-15 mode driving pattern. Three different operating modes have been presented, and the converter was driven by two different modulations under the 10-15 mode cycle. The data shows that in order to achieve the highest efficiency, the proposed circuit needs to operate under particular circumstances. For instance, Mode III is able to achieve the highest efficiency while operating under PWM for low-speed drive, and the battery power should be designed to be approximately $20 \%$ of the output power.

\section{References}

( 1 ) J.W. Kolar, T. Friedli, J. Rodriguez, and P.W. Wheeler: "Review of Threephase PWM AC-AC Converter Topologies", IEEE Trans. Ind. Applicat., Vol.58, No.11, pp.4988-5006 (2011-11)

( 2 ) T. Friedli, S.D. Round, D. Hassler, and J.W. Kolar: "Design and Performance of a $200 \mathrm{kHz}$ All SiC JFET Current DC-Link Back to Back Converter", IEEE Trans. Ind. Applicat., Vol.45, No.5, pp.1868-1878 (2009-9/10)

( 3 ) J. Andreu, I. Kortabarria, E. Ormaetxea, E. Ibarra, J.L. Martin, and S. Apinaniz: "A Step Forward Towards the Development of Reliable Matrix Converters", IEEE Trans. Ind. Applicat., Vol.59, No.1, pp.167-183 (2012-1) 
( 4 ) R.W.G. Bucknall and K.M. Ciaramella: "On the Conceptual Design and Performance of a Matrix Converter for Marine Electric Propulsion", IEEE Trans. Power Electronics, Vol.25, No.6, pp.1497-1508 (2010-6)

( 5 ) T. Wijekoon, C. Klumpner, P. Zanchetta, and P.W. Wheeler: "Implementation of a Hybrid AC-AC Direct Power Converter with Unity Voltage Transfer", IEEE Trans. Power Electronics, Vol.23, No.4, pp.1918-1926 (2008-7)

( 6 ) C. Klumpner and C. Pitic: "Hybrid matrix converter topologies: An exploration of benefits", in Power Electronics Specialists Conference, pp.2-8, 1519 (2008-6)

( 7 ) J. Itoh and H. Tamura: "A Control Strategy for a Parallel Connected System with a Matrix Converter and a Voltage Source Inverter", IEEJ Trans. IA, Vol.130, No.2, pp.129-137 (2010)

( 8 ) T.D. Nguyen and H.-H. Lee: "Modulation Strategies to Reduce Commonmode Voltage for Indirect Matrix Converters", IEEE Trans. Ind. Electronics, Vol.59, No.1, pp.129-140 (2012-1)

( 9 ) M. Jussila and H. Tuusa: "Comparison of Simple Control Strategies of SpaceVector Modulated Indirect Matrix Converter Under Distorted Supply Voltage", IEEE Trans. Power Electronics, Vol.22, No.1, pp.139-148 (2007-1)

(10) J. Schonberger, T. Friedli, S.D. Round, and J.W. Kolar: "An Ultra Sparse Matrix Converter with a Novel Active Clamp Circuit", in Power Conversion Conference-Nagoya, pp.784-791 (2007-4)

(11) G.T. Chiang and J. Itoh: "DC/DC Boost Converter Functionality in a ThreePhase Indirect Matrix Converter", IEEE Trans. Power Electronics, Vol.26, No.5, pp.1599-1607 (2011-5)

(12) G.T. Chiang and J. Itoh: "Voltage transfer ratio improvement of an Indirect Matrix Converter by Single Pulse Modulation", in Energy Conversion Congress and Exposition, pp.1830-1837 (2010-9)

(13) Ministry of Land, Infrastructure, Transport and Tourism, Japan http://www. mlit.go.jp/jidosha/nenpi/nenpilist/nenpilist.html

(14) G.T. Chiang and J. Itoh: "Performance optimization of a square wave operation in an Indirect matrix converter with a reactor free DC boost converter", in $14^{\text {th }}$ European Conference on Power Electronics and Applications, pp.1-10 (2011-9)

(15) A. Ecklebe, A. Lindemann, and S. Schulz: "Bidirectional Switch Commutation for a Matrix Converter Supplying a Series Resonant Load", IEEE Trans. Power Electronics, Vol.24, No.5, pp.1173-1181 (2009-5)

(16) Plexim GmbH, http://www.plexim.com/
(17) IGBT Discrete 1MBH30D-060, http://www.fujielectric.com/products/ semiconductor/products/powerdevices/discrete.html

(18) IGBT Discrete 2MBI50N-060, http://www.fujielectric.com/products/ semiconductor/products/powerdevices/discrete.html

(19) Y. Yinglin, M. Parten, J. Berg, and T. Maxwell: "Modeling and control of a hybrid electric vehicle", in IEEE Vehicular Technology Conference, Vol.5, pp.2095-2100 (2000-9)

Goh Teck Chiang (Student Member) received his B.S. degree in

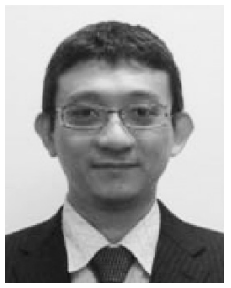
electrical and electronic engineering from Queensland University of Technology, Brisbane, Australia in 2004 and his M.S. degree in electrical and electronic engineering from Nagaoka University of Technology, Japan in 2009, where he is currently working towards a Ph.D. degree in electrical and electronic engineering. His research interests include indirect matrix converters and PWM.

Jun-ichi Itoh (Member) received his M.S. and Ph.D. degrees in elec-

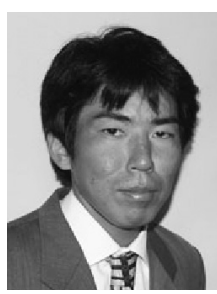
trical and electronic systems engineering from $\mathrm{Na}$ gaoka University of Technology, Nagaoka, Japan in 1996 and 2000, respectively. From 1996 to 2004, he was with Fuji Electric Corporate Research and Development Ltd., Tokyo, Japan. Since 2004, He has been with Nagaoka University of Technology as an associate professor. He received the IEEJ Academic Promotion Award (IEEJ Technical Development Award) in 2007. His research interests include matrix converters, DC/DC converters, power factor correction techniques, and motor drives. 